\title{
On Comparative Quantification in the Verbal Domain *
}

\author{
Kimiko Nakanishi \\ University of Connecticut
}

\section{Introduction}

The central goal of this paper is to provide a mechanism of comparative quantification in the verbal domain, where the degree of comparison is associated with an event argument. The empirical data comes from the comparative construction in Japanese with sugiru, which is an intransitive verb meaning 'to pass, to exceed', as in (1)a. Sugiru can attach to an adjective or a verb and express excessiveness just like too in English, as in (1)b-c.
a. Simekiri-ga sugi-ta.
deadline-NOM exceed-PAST 'The deadline has passed.'
b. Kono sukaato-ga naga-sugi-ru. this skirt-NOM long-exceed-PRES 'This skirt is too long.'
c. John-ga ne-sugi-ta.
John-NOM sleep-too much-PAST 'John slept too much.'

When -sugiru occurs with a measure phrase (MP), we observe strikingly different semantic interpretations depending where the MP appears. For instance, (2)a with the MP adjacent to the measured noun means that John overdid the reading of three particular books (read them too many times or for too long). In contrast, (2)b with the 'split' MP means that John read three more books than he was supposed to (e.g. he was supposed to read five, but ended up reading eight). One of the central questions addressed in this paper is how to obtain these two readings. I show that -sugiru in these examples involves comparative quantification in the verbal domain, which calls for a homomorphism (or a structure-preserving mapping) from events to anther domain. The difference comes from the fact that, in (2)b, the MP specifies that a homomorphism is from events to individuals (i.e. from reading events to books), while the MP in (2)a does not.
a. John-ga [hon san-satu]-o
kinoo yomi-sugi-ta.
John-NOM [book three-CL(ASSIFIER)]-ACC yesterday read-exceed-PAST 'John read (the) three books too much yesterday.'
b. John-ga hon-o kinoo san-satu yomi-sugi-ta.
John-NOM book-ACC yesterday three-CL read-exceed-PAST
'John read three books too many yesterday.'


Section 2 presents a brief summary of the previous studies on comparative constructions. In section 3, I show that -sugiru is a comparative quantifier which is analogous to too in English. I argue that -sugiru in the V-sugiru construction expresses excessiveness of 'events'. In section 4, I extend the proposed analysis to too many / too much in English. Section 5 is a conclusion of this paper.

\section{Assumptions on Comparative Constructions}

\subsection{Adjectival Comparatives}

This section briefly summarizes the existing analyses of adjectival comparatives (see also Kennedy 1999). Gradable adjectives such as tall and dense denote relations between individuals and degrees, as in (3). They are monotone, satisfying the definition in (4). The LF and the compositional semantics of John is six feet tall are given in (5). The denotation of the MP six feet, which is a degree phrase (DegP), is a degree argument of type $\mathrm{d}$, and it directly combines with the adjective.

$$
\llbracket \text { tall } \rrbracket=\lambda \mathrm{d}_{\mathrm{d}} \cdot \lambda \mathrm{x}_{\mathrm{e}} \cdot \operatorname{tall}(\mathrm{x}, \mathrm{d}) \quad \text { i.e. } \mathrm{x} \text { is tall to degree } \mathrm{d}
$$

(4) A function $f$ of type $<\mathrm{d}$,et $>$ is monotone iff

$$
\forall \mathrm{x} \forall \mathrm{d} \forall \mathrm{d}^{\prime}\left[\mathrm{f}(\mathrm{d})(\mathrm{x})=1 \wedge \mathrm{d}^{\prime}<\mathrm{d} \rightarrow \mathrm{f}\left(\mathrm{d}^{\prime}\right)(\mathrm{x})=1\right]
$$

(5) LF: John is [AP [DegP six feet] tall]

a. $\llbracket$ six feet $\rrbracket=6$,

b. 【John is six feet tall $\rrbracket=\operatorname{tall}\left(\mathrm{j}, 6^{\prime}\right)$

A DegP can be a complex predicate headed by -er, as in -er than six feet. The comparative morpheme -er is a determiner of type $\langle\mathrm{dt},\langle\mathrm{dt}, \mathrm{t}\rangle\rangle$, which takes two sets of degrees and compares the maximal values of these two sets, as in (6). ' $m a x$ ' is a function from a set $\mathrm{D}$ of degrees to the degree $\mathrm{d}$ in $\mathrm{D}$ such that, for all other degrees d' in D, d is greater or equal to d', as defined in (7) (cf. Rullmann 1995:54).

$$
\begin{aligned}
& \llbracket-e r \rrbracket=\lambda D_{<d, t>} \cdot \lambda D^{\prime}<d, t>\cdot \max \left(D^{\prime}\right)>\max (D) \\
& \max (D):=\text { td. } D(d)=1 \wedge \forall d^{\prime}\left[D\left(d^{\prime}\right)=1 \rightarrow d^{\prime} \leq d\right]
\end{aligned}
$$

The DegP -er than six feet is a generalized quantifier over degrees. In John is taller than six feet, the DegP undergoes quantifier raising, leaving a trace of type d: ${ }^{1}$

(8) LF: [DegP -er than 6 feet $]_{1}\left[\right.$ IP John is [AP $t_{1}$ tall $\left.]\right]$

a. 【John is $\mathrm{t}_{1}$ tall $\rrbracket^{\mathrm{g}}=\operatorname{tall}(\mathrm{j}, \mathrm{g}(1))$

b. $\llbracket 1 I P \rrbracket^{g}=\lambda d_{d} \cdot \llbracket I P \rrbracket^{g d / 1}=\lambda d_{d} \cdot \operatorname{tall}(j, g d / 1(1))=\lambda d_{d} \cdot \operatorname{tall}(j, d)^{2}$ 
c. $\llbracket$-er than six feet $\rrbracket^{\mathrm{g}}=\lambda \mathrm{D}^{\prime}<\mathrm{d}, \mathrm{t}>\mathrm{max}\left(\mathrm{D}^{\prime}\right)>6^{\prime}$

d. 【John is taller than six feet $\rrbracket^{\mathrm{g}}=\max \{\mathrm{d}: \operatorname{tall}(\mathrm{j}, \mathrm{d})\}>6^{\prime}$

The -er comparative construction can have a differential MP (von Stechow 1984), such as one inch in John is one inch taller than Mary. The denotation of -er that takes a differential MP is given in (9). ${ }^{3}$ The mathematical operations of subtraction $(-)$ and equalization $(=)$ require the three relevant degrees - that is, $\max \left(D^{\prime}\right), \max (D)$, and $d-$ to be of the same sort, which excludes deviant examples like *John is two pounds taller than Mary, where degrees are not of the same sort.

$$
\llbracket-e r \rrbracket=\lambda \mathrm{D}_{<\mathrm{d}, \mathrm{t}>} \cdot \lambda \mathrm{d}_{\mathrm{d}} \cdot \lambda \mathrm{D}^{\prime}<\mathrm{d}, \mathrm{t}>\cdot \max \left(\mathrm{D}^{\prime}\right)-\max (\mathrm{D})=\mathrm{d}
$$

(10) LF: [DegP one inch -er than Mary $]_{1}$ [IP John is [AP $t_{1}$ tall]]

a. $\llbracket 1 \mathrm{IP} \rrbracket^{\mathrm{g}}=\lambda \mathrm{d}_{\mathrm{d}} \cdot \llbracket I P \rrbracket^{\mathrm{g} / 1}=\lambda \mathrm{d}_{\mathrm{d}} \cdot \operatorname{tall}(\mathrm{j}, \mathrm{g} / 1 \mathrm{~d}(1))=\lambda \mathrm{d}_{\mathrm{d}} \cdot \operatorname{tall}(\mathrm{j}, \mathrm{d})$

b. 【one inch -er than Mary $\rrbracket^{\mathrm{g}}=\lambda \mathrm{D}^{\prime}<\mathrm{d}, \mathrm{t}>\max \left(\mathrm{D}^{\prime}\right)-\max \{\mathrm{d}: \operatorname{tall}(\mathrm{m}, \mathrm{d})\}=1$ "

c. $\llbracket J o h n$ is 1 " taller than Mary $\rrbracket^{\mathrm{g}}=\max \{\mathrm{d}: \operatorname{tall}(\mathrm{j}, \mathrm{d})\}-\max \{\mathrm{d}: \operatorname{tall}(\mathrm{m}, \mathrm{d})\}=1$ "

\subsection{Comparative Quantification in the Nominal Domain}

It has been argued that a complex determiner such as more than six is decomposed into MANY followed by the DegP -er than six. Hackl (2000) proposes the denotation of MANY in (11), where MANY takes a degree argument and yields the characteristic function of a set of individuals that are numerous to degree $d{ }^{4}$ In this analysis, what MANY does is to associate a degree argument with the cardinality of a (pluralized) individual x. (12) spells out the LF and the compositional semantics of more than six boys danced. The *-operator is an operator for semantic pluralization that applies to a one-place predicate $P$ and generates all the individual sums of members of the extensions of $P$, as exemplified in (13) (Link 1983). ${ }^{5}$

$$
\llbracket \text { MANY }=\lambda \mathrm{d}_{\mathrm{d}} \cdot \lambda \mathrm{x}_{\mathrm{e}} \cdot|\mathrm{x}|=\mathrm{d}
$$

(12) LF: [DegP -er than 6 $]_{1}\left[\right.$ IP [DP $\mathrm{t}_{1}$ MANY boys] danced]

a. $\llbracket \mathrm{t}_{1} \mathrm{MANY} \rrbracket^{\mathrm{g}}=\lambda \mathrm{x}_{\mathrm{e}} \cdot|\mathrm{x}|=\mathrm{g}(1)$

b. $\llbracket \mathrm{DPP} \rrbracket^{\mathrm{g}}=\lambda \mathrm{x}_{\mathrm{e}} \cdot{ }^{*} \operatorname{boy}(\mathrm{x}) \wedge|\mathrm{x}|=\mathrm{g}(1)$

$\exists:<\mathrm{e}, \mathrm{t}>\rightarrow<\mathrm{et}, \mathrm{t}>\quad \exists \mathrm{X}=\lambda \mathrm{P}<\mathrm{e}, \mathrm{t}>. \exists \mathrm{y}[\mathrm{X}(\mathrm{y}) \wedge \mathrm{P}(\mathrm{y})] \quad$ (Partee 1987)

c. $\exists+\llbracket \mathrm{DP} \rrbracket^{\mathrm{g}}=\lambda \mathrm{P} . \exists \mathrm{y}\left[{ }^{*} \operatorname{boy}(\mathrm{y}) \wedge|\mathrm{y}|=\mathrm{g}(1) \wedge \mathrm{P}(\mathrm{y})\right]$

d. $\llbracket 1 \mathrm{IP} \rrbracket^{\mathrm{g}}=\lambda \mathrm{d}_{\mathrm{d}}$. $\llbracket \mathrm{IP} \rrbracket^{\mathrm{gd} / 1}=\lambda \mathrm{d}_{\mathrm{d}} . \exists \mathrm{y}\left[{ }^{*} \operatorname{boy}(\mathrm{y}) \wedge|\mathrm{y}|=\mathrm{d} \wedge *\right.$ dance $\left.(\mathrm{y})\right]$

e. $\llbracket$-er than six $\rrbracket^{\mathrm{g}}=\lambda \mathrm{D}^{\prime}<\mathrm{d}, \mathrm{t}>\max \left(\mathrm{D}^{\prime}\right)>6$

f. $\max \left\{\mathrm{d}: \exists \mathrm{y}\left[{ }^{*} \operatorname{boy}(\mathrm{y}) \wedge|\mathrm{y}|=\mathrm{d} \wedge{ }^{*}\right.\right.$ dance $\left.\left.(\mathrm{y})\right]\right\}>6$

'The maximal degree $d$ such that $d$-many boys danced exceeds six.'

a. $\llbracket b o y \rrbracket=\{\mathrm{x}, \mathrm{y}, \mathrm{z}\}$

$\llbracket{ }^{*}$ boy $\rrbracket=\left\{\mathrm{x}, \mathrm{y}, \mathrm{z}, \mathrm{x} \cup_{\mathrm{I}} \mathrm{y}, \mathrm{x} \cup \mathrm{I} \mathrm{Z}, \mathrm{y} \cup_{\mathrm{I}} \mathrm{z}, \mathrm{x} \cup_{\mathrm{I}} \mathrm{y} \cup_{\mathrm{I}} \mathrm{Z}\right\}$ 
b. $\llbracket$ dance $\rrbracket=\left\{\mathrm{e}_{1}, \mathrm{e}_{2}, \mathrm{e}_{3}\right\}$

【*dance $\rrbracket=\left\{\mathrm{e}_{1}, \mathrm{e}_{2}, \mathrm{e}_{3}, \mathrm{e}_{1} \cup \cup_{\mathrm{E}} \mathrm{e}_{2}, \mathrm{e}_{1} \cup_{\mathrm{E}} \mathrm{e}_{3}, \mathrm{e}_{2} \cup_{\mathrm{E}} \mathrm{e}_{3}, \mathrm{e}_{1} \cup_{\mathrm{E}} \mathrm{e}_{2} \cup_{\mathrm{E}} \mathrm{e}_{3}\right\}$

\subsection{The Semantics of Too}

In this section, I propose a (simplified) semantics of too, which later provides an adequate tool to express the parallelism between comparative quantifications in the nominal and verbal domains. ${ }^{6}$ Most notably, Heim (2000) and Meier (2003) consider the too construction as a comparison between two values, where the standard of comparison is modalized. In this paper, I pursue Heim's and Meier's idea that too is a comparison between two sets of degrees, but I will simplify their analysis by not modalizing the standard of comparison. Recall that -er expresses a comparison between two maximal values, one associated with a main clause and the other with a than-clause (see (6)). Like -er, too is a comparison between two maximal values. However, instead of the maximal value associated with a than-clause, too takes a context-sensitive value $\mathrm{C}$ provided by context, as in (14). For example, as in (15), the LF of John is too tall is analogous to the LF of -er comparatives (see (8), for instance). The sentence is true if the maximal degree $d$ such that John is d-tall is greater than C (e.g. a standard degree of tallness).

a. $\llbracket$ too $\rrbracket=\lambda \mathrm{D}_{<\mathrm{d}, \mathrm{t}>} \cdot \max (\mathrm{D})>\mathrm{C}$

b. $\llbracket t o o \rrbracket=\lambda \mathrm{d}_{\mathrm{d} .} \cdot \lambda \mathrm{D}_{<\mathrm{d}, \mathrm{t}>} \cdot \max (\mathrm{D})-\mathrm{C}=\mathrm{d} \quad$ (with a differential MP)

(15) LF: [DegP too $]_{1}\left[\right.$ IP John is [AP $t_{1}$ tall $\left.]\right]$

a. $\llbracket 1 \mathrm{IP} \rrbracket^{\mathrm{g}}=\lambda \mathrm{d}_{\mathrm{d}} \cdot \llbracket I P \rrbracket^{\mathrm{gd} / 1}=\lambda \mathrm{d}_{\mathrm{d}} \cdot \operatorname{tall}\left(\mathrm{j}, \mathrm{g}^{\mathrm{d} / 1}(1)\right)=\lambda \mathrm{d}_{\mathrm{d}} \cdot \operatorname{tall}(\mathrm{j}, \mathrm{d})$

b. $\llbracket$ John is too tall $\rrbracket]^{\mathrm{g}}=\max \{\mathrm{d}$ : tall $(\mathrm{j}, \mathrm{d})\}>\mathrm{C}$

Just like -er, too can occur in the nominal domain, as in too many boys danced in (16) (see section 4 for more examples). We saw in section 2.2 that more than six is decomposed to MANY and the DegP -er than six. The decomposition of too many is obvious from the surface syntax: many and the DegP too.

LF: [DegP too $]_{1}\left[\right.$ [PP [DP $t_{1}$ many boys] danced]

a. $\llbracket 1 \mathrm{IP} \rrbracket^{\mathrm{g}}=\lambda \mathrm{d}_{\mathrm{d}} . \exists \mathrm{y}[* \operatorname{boy}(\mathrm{y}) \wedge|\mathrm{y}|=\mathrm{d} \wedge *$ dance $(\mathrm{y})]$

(see (12))

b. $\max \{\mathrm{d}: \exists \mathrm{y}[* \operatorname{boy}(\mathrm{y}) \wedge|\mathrm{y}|=\mathrm{d} \wedge * \operatorname{dance}(\mathrm{y})]\}>\mathrm{C}$

\section{The Semantics of -Sugiru 'to exceed' as a Comparative Quantifier}

We are now ready to examine the data with -sugiru in Japanese. In section 3.2, I propose an analysis for -sugiru when it attaches to an adjective. By assuming that the denotation of -sugiru in this sequence is analogous to that of too in English, we obtain correct interpretations of the sentences. In section 3.3, I discuss examples 
where-sugiru attaches to a verb. I claim that -sugiru is decomposed into two parts: a part which expresses excessiveness as DegP too and a part which relates degrees with events (cf. MANY in (11)). I further argue that there is a homomorphism from events to other domains such as times, paths, individuals, etc.

\subsection{Syntactic Assumptions}

Before examining the semantics of -sugiru, some syntactic assumptions need to be stated. I assume that verbs have an extra slot for the event argument (Davidson 1967). Moreover, I adopt Kratzer's (1996, to appear) syntactic structure and semantic computation given in (17). I use type $\mathrm{v}$ for events.

(17)

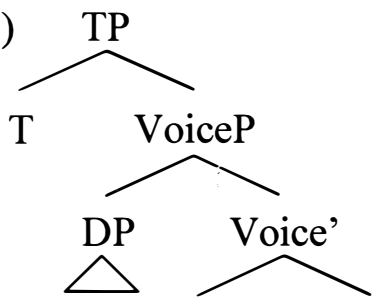

John Voice

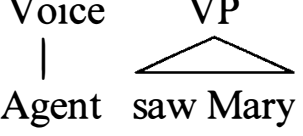

$$
\llbracket s e e \rrbracket=\lambda \mathrm{x}_{\mathrm{e}} \cdot \lambda \mathrm{e}_{\mathrm{v}} \cdot{ }^{*} \operatorname{see}(\mathrm{x}, \mathrm{e})
$$$$
\llbracket \text { see Mary }=\lambda \mathrm{e}_{\mathrm{v}}{ }^{*} \mathrm{see}(\mathrm{m}, \mathrm{e})
$$$$
\llbracket \text { Agent } \rrbracket=\lambda \mathrm{x}_{\mathrm{e}} \cdot \lambda \mathrm{e}_{\mathrm{v}} \cdot \operatorname{Agent}(\mathrm{e})=\mathrm{x}
$$$$
\llbracket \text { Voice' } \rrbracket=\lambda \mathrm{x}_{\mathrm{e}} \cdot \lambda \mathrm{e}_{\mathrm{v}} \cdot \operatorname{Agent}(\mathrm{e})=\mathrm{x} \wedge{ }^{*} \operatorname{see}(\mathrm{m}, \mathrm{e})^{7}
$$$$
\llbracket \text { VoiceP》 }=\lambda \mathrm{e}_{\mathrm{v}} \text {. Agent }(\mathrm{e})=\mathrm{j} \wedge * \operatorname{see}(\mathrm{m}, \mathrm{e})
$$$$
\llbracket T P \rrbracket=\exists e\left[\operatorname{Agent}(\mathrm{e})=\mathrm{j} \wedge{ }^{*} \operatorname{see}(\mathrm{m}, \mathrm{e})\right]
$$

-Sugiru in V-sugiru is considered to be a raising verb that takes a sentential complement, as in (18) (Sugioka 1985, Kageyama and Yumoto 1997, Koizumi 1998). In contrast, -sugiru with an adjective first combines with the adjective, and the complex predicate adjective+-sugiru combines with the subject. This is analogous to too in English whose structure is given in (19)a. Indeed, in section 3.2, I claim that -sugiru with adjectives is semantically the same as too in English. Thus, I assume the structure in (19)b, abstracting away from the existence of VoiceP.

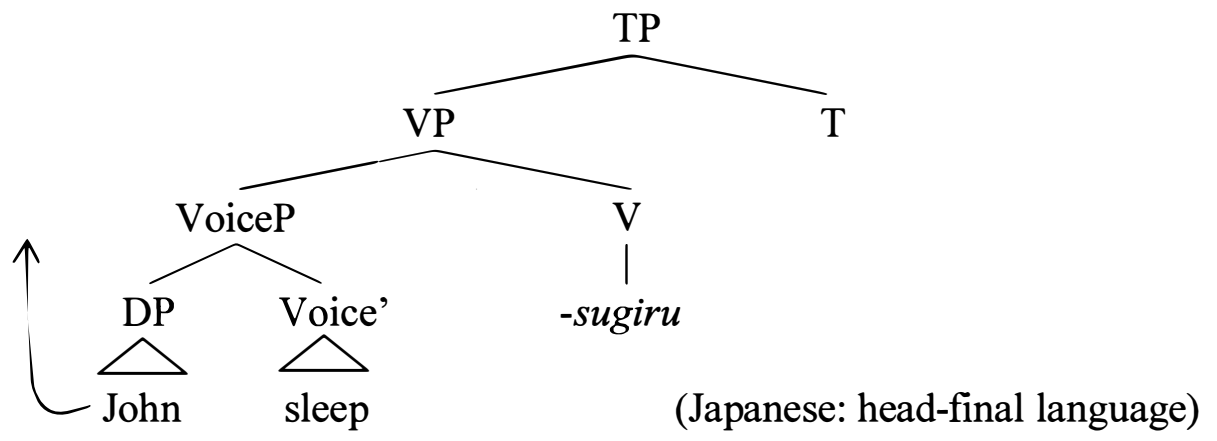

(19) a. English too comparative: [IP John [VP is [AP too tall]]]

b. Japanese -sugiru comparative: [IP John [VP tall -sugiru] 


\subsection{Adjectival Comparatives}

Let us first examine the semantics of -sugiru with adjectives. (20) shows that, like too in English, -sugiru is compatible with open scale adjectives (e.g. long, deep, expensive), but not with closed scale adjectives (e.g. empty, open, visible).
a. Kono sukaato-ga naga-sugi-ru. this skirt-NOM long-exceed-PRES 'This skirt is too long.'
b. *Kono hako-ga kara-sugi-ru. this box-NOM empty-exceed-PRES *'This box is too empty.'

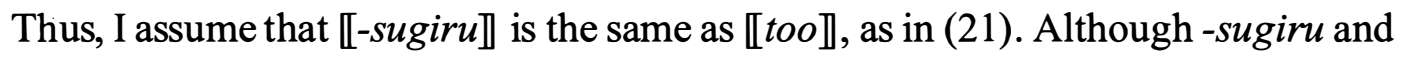
too are syntactically different in that -sugiru is a verb and too is an adverbial element, this difference does not cause any problems for compositionally deriving the interpretation of adjective+-sugiru, as in (22), which correlates with (20)a.

$$
\llbracket-\text { sugiru } \rrbracket=\lambda \mathrm{D}_{<\mathrm{d}, \mathrm{t}>} . \max (\mathrm{D})>\mathrm{C}
$$

(22) LF: [ -sugiru $]_{1}\left[\right.$ IP this skirt [vP long $\left.\left.t_{1}\right]\right]$

a. $\llbracket 1 \mathrm{IP} \rrbracket^{\mathrm{g}}=\lambda \mathrm{d}_{\mathrm{d}}$. $\llbracket I P \rrbracket^{\mathrm{gd} / 1}=\lambda \mathrm{d}_{\mathrm{d}}$. long(this skirt,d)

b. $\llbracket$ this skirt long-sugiru $\rrbracket^{\mathrm{g}}=\max \{\mathrm{d}$ : long(this skirt,d) $\}>\mathrm{C}$

\subsection{Comparative Quantification in the Verbal Domain}

Turning now to the semantics of -sugiru with verbs, I first consider (23), which has the reading that what is excessive is how many times John went shopping.
John-ga kaimono-ni iki-sugi-ta.
John-NOM shopping-to go-exceed-PAST
'John went shopping too many times.'

Based on the structure in (18), -sugiru in (23) combines with the sentential complement John-ga kaimono-ni iki- '(lit.) John go shopping' in the syntax. Assuming that -sugiru is a comparative quantifier over degrees of type $\langle\mathrm{dt}, \mathrm{t}\rangle$, as in (21) above, -sugiru takes a set of degrees as an argument. ${ }^{8}$ However, the sentential complement lacks a degree argument; it simply denotes a set of John's-going-shopping events of type $\langle\mathrm{v}, \mathrm{t}\rangle$. To obtain the relevant interpretation, we need to somehow express '(lit.) John go shopping d-many times'. I argue that this is possible by introducing a component which associates a degree with an event introduced by a sentential complement. This component is analogous to MANY in (11): a complex determiner more than six is decomposed into DegP -er than six and MANY that associates a degree with individuals, which makes the comparative quantifier combinable with the nominal predicate (e.g. boys in more than six boys). 
Similarly, in the verbal domain, -sugiru is semantically decomposed into two parts, as in (24): one part expresses excessiveness like too (in (25)) and the other part, which is expressed as MANY ${ }_{e}$, relates events with degrees (in (26)). ${ }^{9}$

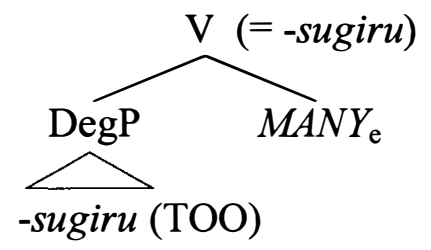

a. $\llbracket$-sugiru $=\lambda \mathrm{D}_{<\mathrm{d}, \mathrm{t} .} \max (\mathrm{D})>\mathrm{C}$

b. $\llbracket$-sugiru $\rrbracket=\lambda \mathrm{d}_{\mathrm{d}} \cdot \lambda \mathrm{D}_{<\mathrm{d}, \mathrm{t}>} . \max (\mathrm{D})-\mathrm{C}=\mathrm{d} \quad$ (with a differential MP)

$$
\llbracket M A N Y_{\mathrm{e}} \rrbracket=\lambda \mathrm{d}_{\mathrm{d}} \cdot \lambda \mathrm{e}_{\mathrm{v}} \cdot|\mathrm{e}|=\mathrm{d} \quad \text { (first version) }
$$

Although a decomposition of a complex determiner such as more than six is morpho-syntactically transparent $($ more $=$ many +- er $)$, -sugiru does not have a morphological realization of the relevant two parts, i.e. MANY and TOO. However, this is true not just for Japanese, but also for languages like Spanish. As shown in (27)a, demasiado is a comparative quantifier like too in English. It can combine with a nominal predicate, as in (27)b, or with a verbal predicate, as in (27)c. ${ }^{10}$ Based on this fact, I assume that a morpho-syntactic decomposition and a semantic decomposition do not always correlate with each other.
a. Esta falda es demasiado larga. this skirt is too much long
'This skirt is too long.'
b. Bailaron demasiados chicos. danced too many boys 'Too many boys danced.'
c. Juan sale de juerga demasiado. Juan goes out of party too much 'Juan goes out partying too much.'

We have now established the analysis of -sugiru as a comparative quantifier in the verbal domain. (28) spells out the LF and compositional semantics of (23).

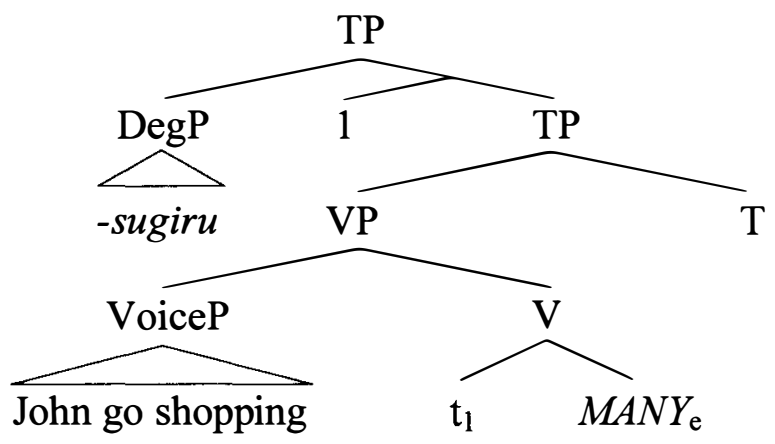


$\llbracket V_{\text {VoiceP }} \rrbracket^{\mathrm{g}}=\lambda \mathrm{e}_{\mathrm{v}}$. Agent $(\mathrm{e})=\mathrm{j} \wedge{ }^{*}$ go.shopping(e) $\quad($ see $(17))$

$\llbracket \mathrm{t}_{1} \mathrm{MANY}_{\mathrm{e}} \rrbracket^{\mathrm{g}}=\lambda \mathrm{e}_{\mathrm{v}} \cdot \mathrm{e} \mid=\mathrm{g}(1)$

$\llbracket V P \rrbracket^{g}=\lambda e_{v}$. Agent $(e)=j \wedge *$ go.shopping $(e) \wedge|e|=g(1)$

$\llbracket \mathrm{TP} \rrbracket^{\mathrm{g}}=\exists \mathrm{e}$ [Agent $(\mathrm{e})=\mathrm{j} \wedge{ }^{*}$ go.shopping $\left.(\mathrm{e}) \wedge|\mathrm{e}|=\mathrm{g}(1)\right]$

$\llbracket 1 \mathrm{TP} \rrbracket^{\mathrm{g}}=\lambda \mathrm{d}_{\mathrm{d}} \cdot \llbracket \mathrm{TP} \rrbracket^{\mathrm{g} d / 1}=\lambda \mathrm{d}_{\mathrm{d}} . \exists \mathrm{e}\left[\operatorname{Agent}(\mathrm{e})=\mathrm{j} \wedge *^{*}\right.$ go.shopping(e) $\left.\wedge|\mathrm{e}|=\mathrm{d}\right]$

$\llbracket \mathrm{DegP} \rrbracket^{\mathrm{g}}=\lambda \mathrm{D}_{<\mathrm{d}, \mathrm{t}>} \cdot \max (\mathrm{D})>\mathrm{C}$

$\llbracket \mathrm{TP} \rrbracket^{\mathrm{g}}=\max \left\{\mathrm{d}: \exists \mathrm{e}\left[\right.\right.$ Agent $(\mathrm{e})=\mathrm{j} \wedge *^{*}$ go.shopping $\left.\left.(\mathrm{e}) \wedge|\mathrm{e}|=\mathrm{d}\right]\right\}>\mathrm{C}$

'The maximal degree $\mathrm{d}$ such that there is a plural John's-going-shopping event e whose cardinality (of atomic events) is d-many exceeds C.'

(23) can take a differential MP like san-kai 'three times', as in (29). The LF and compositional semantics of (29)a are given in (30).
John-ga
konsyuu
kaimono-ni san-kai
iki-sugi-ta.
John-NOM
this week shopping-to three-time
go-exceed-PAST

'John went shopping three times too many this week.'

(30) LF: [DegP three times -sugiru $]_{1}\left[\mathrm{TP}\right.$ John went shopping $\mathrm{t}_{1}$ MANY]

a. $\quad \llbracket 1 \mathrm{TP} \rrbracket^{\mathrm{g}}=\lambda \mathrm{d}_{\mathrm{d}} . \exists \mathrm{e}\left[\operatorname{Agent}(\mathrm{e})=\mathrm{j} \wedge{ }^{*}\right.$ go.shopping(e) $\left.\wedge|\mathrm{e}|=\mathrm{d}\right] \quad(\operatorname{see}(28))$

b. $\llbracket \mathrm{DegP} \rrbracket^{\mathrm{g}}=\lambda \mathrm{D}_{<\mathrm{d}, \triangleright}$. $\max (\mathrm{D})-\mathrm{C}=3$ times

c. $\max \left\{\mathrm{d}: \exists \mathrm{e}\left[\operatorname{Agent}(\mathrm{e})=\mathrm{j} \wedge{ }^{*}\right.\right.$ go.shopping $\left.\left.(\mathrm{e}) \wedge|\mathrm{e}|=\mathrm{d}\right]\right\}-\mathrm{C}=3$ times

'The maximal degree $d$ s.t. there is a plural John's-going-shopping event $e$ whose cardinality (of atomic events) is d-many exceeds $\mathrm{C}$ by 3 times.'

Excessiveness in V-sugiru is not just with respect to the cardinality of events. For instance, (31)a refers to the excessive amount of time that John slept, and (31)b means that John swam three miles excessively in terms of distance. To account for these examples, I propose (32), where $\mu$ is a measure function and a degree $d$ is obtained by applying $\mu$ to the relevant event e. Following Schwarzschild (2002), I assume that $\mu$ is a measurement scheme (e.g. cardinality, temporal/spatial length, etc.) obtained from context. (31)a and (31)b involve $\mu$ : temporal-length and $\mu$ : spatial-length, respectively, and (29) involves $\mu$ : cardinality-of-events.

a. John-ga san-jikan ne-sugi-ta. John-NOM three-hour sleep-exceed-PAST 'John slept three hours too long.'

b. John-ga san-mairu oyogi-sugi-ta. John-NOM three-mile swim-exceed-PAST 'John swam three miles too far.'

$\llbracket M A N Y_{e} \rrbracket=\lambda d_{d} \cdot \lambda e_{v} \cdot \mu(e)=d$ (revised version)

Note that $\mu$ cannot always apply to events directly. What is relevant for us here is Krifka's (1989) claim that temporal adverbials like for three hours in 'John 
slept for three hours' cannot measure events directly, but they can measure entities which bear a relation to events, most notably times. That is, for three hours indirectly measures the sleeping event by measuring the run time of the event. Formally, he assumes that there is a homomorphism $h$ from events $\mathrm{E}$ to event run times $\mathrm{T}$, with $h\left(\mathrm{e}_{1} \cup_{\mathrm{E}} \mathrm{e}_{2}\right)=h\left(\mathrm{e}_{1}\right) \cup_{\mathrm{T}} h\left(\mathrm{e}_{2}\right)$, where $\cup_{\mathrm{E}}$ and $\cup_{\mathrm{T}}$ are sum operators for events and times, respectively. ${ }^{11}$ In the same vein, in (31)a, the John's-sleeping event per se cannot be directly measured by $\mu$ : temporal-length, but its run time can. Thus, $\mu$ applies to run times mapped from events by $h$. Likewise, in (31)b, $\mu$ : spatial-length applies to paths mapped from events by $h .^{12}$

Let us now examine the compositional semantics of (31)a spelled out in (33). As discussed in section 2.2, the mathematical operations ( - and $=$ ) in (33)b require the three relevant degrees, i.e. $\max (\mathrm{D}), \mathrm{C}$, and 3 hours, to be of the same sort. Since 3 hours is a temporal expression, $\max (\mathrm{D})$ and $\mathrm{C}$ must also be temporal expressions. $\mathrm{D}$ in $\max (\mathrm{D})$ is saturated by a set of degrees in (33)a, hence $\max (\mathrm{D})$ would be $\max \{\mathrm{d}: \exists \mathrm{e}[\operatorname{Agent}(\mathrm{e})=\mathrm{j} \wedge * \operatorname{sleep}(\mathrm{e}) \wedge \mu(\mathrm{e})=\mathrm{d}]\}$, as in (33)c. For $\max (\mathrm{D})$ to express a time, the relevant measure function must be $\mu$ : temporal-length. As discussed shortly above, $\mu$ : temporal-length cannot directly apply to events, but to times. Thus, in (33)c, a homomorphism $h$ from events to temporal traces is introduced by a type-mismatch rule, yielding the sub-formula $\mu(h(\mathrm{e}))=\mathrm{d}$. The same analysis obtains for (31)b, where the relevant measure function is $\mu$ : spatial-length, which requires a homomorphism from events to their paths.

(33) LF: [DegP three hours -sugiru $]_{1}$ [TP John slept $t_{1}$ MANY]

a. $\llbracket 1 \mathrm{TP} \rrbracket^{\mathrm{g}}=\lambda \mathrm{d}_{\mathrm{d}} . \exists \mathrm{e}\left[\operatorname{Agent}(\mathrm{e})=\mathrm{j} \wedge *^{*} \operatorname{sleep}(\mathrm{e}) \wedge \mu(\mathrm{e})=\mathrm{d}\right]$

b. $\llbracket \mathrm{DegP} \rrbracket^{\mathrm{g}}=\lambda \mathrm{D}_{<\mathrm{d}, \mathrm{t}>} \cdot \max (\mathrm{D})-\mathrm{C}=3$ hours

c. $\max \left\{\mathrm{d}: \exists \mathrm{e}\left[\operatorname{Agent}(\mathrm{e})=\mathrm{j} \wedge *^{*} \operatorname{sleep}(\mathrm{e}) \wedge \mu(h(\mathrm{e}))=\mathrm{d}\right]\right\}-\mathrm{C}=3$ hours

'The maximal degree $d$ such that there is a plural John's-sleeping event $\mathrm{e}$ which is mapped to d-long time exceeds $\mathrm{C}$ by three hours.'

In sum, in (29) and (31), the differential MPs (san-kai 'three times', san-jikan 'three hours', san-mairu 'three miles') indicate which measure function $\mu$ is needed. If $\mu$ cannot directly apply to events, we need to introduce a homomorphism from events to other domain where $\mu$ is applicable:
a. three times $\rightarrow \mu$ : cardinality-of-events, no $h$ required
b. three hours $\rightarrow \mu$ : temporal-length, $h$ from events to temporal traces
c. three miles $\rightarrow \mu$ : spatial-length, $h$ from events to paths

It is predicted that, without differential MPs, we obtain an ambiguity of interpretation: when a measure function is not specified by a differential MP, there should be some flexibility in choosing which measure function is relevant. This prediction is borne out, as in (35), which corresponds to (31). For instance, (35)b can express the excessiveness of cardinality of events, of temporal distance, or of 
spatial distance. Any measure function can be used as long as it is compatible with the relevant event. Such a condition explains why (35)a lacks a spatial length interpretation: it does not make sense for the sleeping event to have a spatial length.
a. John-ga
ne-sugi-ta.
John-NOM
sleep-exceed-PAST
'John slept too much.' (too many times, too long)
b. John-ga
oyogi-sugi-ta.
John-NOM
swim-too much-PAST
'John swam too much.' (too many times, too long, too far)

The generalization so far then is that a differential MP signals what kind of measure function $\mu$ for events is needed, which in turn determines what kind of homomorphism $h$ is called for. The relation between the measure function $\mu$ and the homomorphism $h$ is schematized in (36). Possible combinations of the two are not completely random. We first obtain a measure function that can be indicated by a differential MP, if any, or that can be specified by a relevant context. Then the measure function determines what kind of homomorphism is required.

$$
\begin{aligned}
& \mu_{\sigma}\left(h_{\tau}(\mathrm{e})\right) \\
& \mu_{1}, \mu_{2}, \mu_{3}, \mu_{4}, \ldots, \mu_{\sigma} \text { (cardinality, temporal-length, spatial-length, etc.) } \\
& h_{1}, h_{2}, h_{3}, h_{4}, \ldots, h_{\tau} \text { (from events to times, to paths, to individuals, etc.) }
\end{aligned}
$$

\subsection{Homomorphism to Individuals}

There is yet another possible interpretation of the V-sugiru construction, as in (37)a, where the sentence has the reading that John read too many books. The availability of this reading becomes apparent in (37)b, where san-satu 'three-CL(ASSIFIER)' specifies the number of books that were excessive.
a. John-ga hon-o kinoo yomi-sugi-ta.
John-NOM book-ACC yesterday read-exceed-PAST
'John read too many books yesterday.'
b. John-ga hon-o kinoo san-satu yomi-sugi-ta.
John-NOM book-ACC yesterday three-CL read-exceed-PAST
'John read three books too many yesterday.'

I propose to analyze (37) $\mathrm{b}$ in a way parallel to the previous examples, treating the MP 'three-CL' as a differential MP, which is the argument of -sugiru. Based on the discussion in section 3.3, 'three-CL' as a differential MP should express which measure function is called for. It is well known that numerals in Japanese must be followed by a classifier, i.e. a morpheme that indicates the semantic class of the host noun in terms of shape, size, animacy, etc. (Downing 1996). A classifier phrase 
such as san-satu 'three-CL' necessarily express the cardinality of individuals of a certain kind (cf. Krifka 1995). Hence, the measure function associated with a classifier phrase is $\mu$ : cardinality-of-individuals. Then, in (38)b, the relevant degree

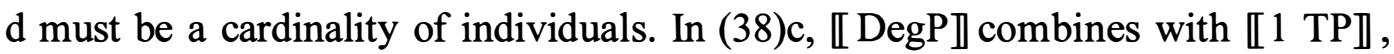
initially yielding the sub-formula $\mu(\mathrm{e})=\mathrm{d}$. However, $\mu$ : cardinality-of-individuals cannot measure events directly; rather, this measure function should apply to individuals. Following the analysis in section 3.3, there needs to be a homomorphism $h$ from events to individuals. ${ }^{13}$ It follows that, in (38)c, $\mu(\mathrm{e})=\mathrm{d}$ needs to be type-shifted to $\mu(h(\mathrm{e}))=\mathrm{d}$, where $h$ is a homomorphism from reading events to books. As a result, $\mu$ : cardinality-of-individuals applies to books, correctly yielding the degree $d$ that expresses a cardinality of books.

(38) LF: [DegP three-CL -sugiru $]_{1}$ [TP John read books $t_{1}$ MANY]

a. $\llbracket 1 \mathrm{TP} \rrbracket^{\mathrm{g}}=\lambda \mathrm{d}_{\mathrm{d}} . \exists \mathrm{e} \exists \mathrm{x}\left[\operatorname{Agent}(\mathrm{e})=\mathrm{j} \wedge * \operatorname{book}(\mathrm{x}) \wedge{ }^{*} \operatorname{read}(\mathrm{x}, \mathrm{e}) \wedge \mu(\mathrm{e})=\mathrm{d}\right]$

b. $\llbracket \mathrm{DegP} \rrbracket^{\mathrm{g}}=\lambda \mathrm{D}_{<\mathrm{d}, \mathrm{t}>} \cdot \max (\mathrm{D})-\mathrm{C}=3$ individuals

c. $\max \left\{\mathrm{d}: \exists \mathrm{e} \exists \mathrm{x}\left[\operatorname{Agent}(\mathrm{e})=\mathrm{j} \wedge{ }^{*} \operatorname{book}(\mathrm{x}) \wedge * \operatorname{read}(\mathrm{x}, \mathrm{e}) \wedge \mu(h(\mathrm{e}))=\mathrm{d}\right]\right\}-\mathrm{C}=$ 3 individuals

'The maximal degree $\mathrm{d}$ such that there is a plural John's reading event $\mathrm{e}$ which is mapped to d-many individuals (namely, books) exceeds $\mathrm{C}$ by three individuals.'

Let us return to the question posed at the beginning of this paper: how can we explain the difference between (2)b (repeated in (37)b) and (2)a (in (39))?

John-ga [hon san-satu]-o kinoo yomi-sugi-ta. John-NOM [book three-CL]-ACC yesterday read-exceed-PAST 'John read (the) three books too much yesterday.' $\quad(=(2) \mathrm{a})$

I argue that the two sentences differ in how the MP san-satu 'three-CL' is syntactically combined with the rest of the sentence. In (37)b, the MP is a differential MP taken as an argument of -sugiru, which signals that the relevant measure function is $\mu$ : cardinality-of-individuals, as shown in (40). Thus, the MP denotes an excessive amount of books. In contrast, in (39), the MP forms a nominal constituent with its host NP, as shown in the structure in (40); hence the sentential complement VoiceP of -sugiru is a non-split MP construction denoting 'John read (the) three books'. If there is no overt differential MP, the excessiveness of -sugiru can be associated with any degree compatible with a reading-three-books event (see (35)). For instance, the measure function can be cardinality-of-events, in which case a homomorphism is not necessary ('John read (the) three books too many times'), or it can be temporal-length, which involves a homomorphism from events to their run times ('John read (the) three books for too long'). Crucially, it cannot be cardinality-of-individuals: the non-split MP in a sentential complement expresses 
the cardinality of books; thus, by the time -sugiru combines with the complement, the cardinality of books is already specified.

(40) LF: [DegP-sugiru $]_{1}\left[\mathrm{TP}\right.$ John read three books $\mathrm{t}_{1}$ MANY]

a. $\quad \llbracket 1 \mathrm{TP} \rrbracket^{\mathrm{g}}=\lambda \mathrm{d}_{\mathrm{d}} . \exists \mathrm{e} \exists \mathrm{x}[\operatorname{Ag}(\mathrm{e})=\mathrm{j} \wedge * \operatorname{book}(\mathrm{x}) \wedge|\mathrm{x}|=3 \wedge * \operatorname{read}(\mathrm{x}, \mathrm{e}) \wedge \mu(\mathrm{e})=\mathrm{d}]$

b. $\llbracket D e g P \rrbracket^{g}=\lambda D_{<d, t>} . \max (\mathrm{D})>C$

c. $\max \{\mathrm{d}: \exists \mathrm{e} \exists \mathrm{x}[\operatorname{Ag}(\mathrm{e})=\mathrm{j} \wedge * \operatorname{book}(\mathrm{x}) \wedge|\mathrm{x}|=3 \wedge * \operatorname{read}(\mathrm{x}, \mathrm{e}) \wedge \mu(\mathrm{e})=\mathrm{d}]\}>\mathrm{C}$

Summing up, we saw in section 3.2 that -sugiru with adjectives has the same distribution as too in English, leading to the claim that -sugiru is semantically analogous to the comparative quantifier too. Section 3.3 presented examples of the V-sugiru construction where -sugiru expresses excessiveness of 'events'. In these examples, I argued that -sugiru is decomposed into two parts: TOO and MANY, where MANY associates events with degrees. When a differential MP is present, it signals which $\mu$ is needed, and further determines which $h$ is called for.

\section{Extensions to Too Many / Too Much in English}

In this section, I extend the analysis of the V-sugiru construction to too many / too much in English. As in (41), too much can express the excessiveness of the cardinality of events, of temporal length, and of spatial length. Hence, I assume that the analysis of -sugiru as comparative quantification in the verbal domain proposed in section 3.3 straightforwardly extends to too much in English in (41).

(41) a. John went shopping (three times) too much.

b. John slept (three hours) too much.

c. John swam (three miles) too much.

My main interest is in too many / too much occurring in the nominal domain, as in John bought too many apples and John drank too much wine. Based on the analysis proposed in section 2.3, the LF and compositional semantics of John bought too many apples are presented in (42). ${ }^{14}$

LF: [DegP too $]_{1}\left[{ }_{1 P}\right.$ John bought [DP $t_{1}$ many apples]]

a. $\llbracket \mathrm{t}_{1}$ many apples $\rrbracket^{\mathrm{g}}=\lambda \mathrm{x}_{\mathrm{e}} \cdot * \operatorname{apple}(\mathrm{x}) \wedge \mu(\mathrm{x})=\mathrm{g}(1)$

b. $\llbracket 1 \mathrm{IP} \rrbracket^{\mathrm{g}}=\lambda \mathrm{d}_{\mathrm{d}} . \exists \mathrm{y}[* \operatorname{apple}(\mathrm{y}) \wedge \mu(\mathrm{y})=\mathrm{g}(1) \wedge *$ buy(j,y) $] \quad(\operatorname{see}(12))$

c. $\llbracket$ too $\rrbracket^{\mathrm{g}}=\lambda \mathrm{D}^{\prime}<\mathrm{d}, \mathrm{t} . \max \left(\mathrm{D}^{\prime}\right)>\mathrm{C}$

d. $\max \{\mathrm{d}: \exists \mathrm{y}[* \operatorname{apple}(\mathrm{y}) \wedge \mu(\mathrm{y})=\mathrm{d} \wedge *$ buy $(\mathrm{j}, \mathrm{y})]\}>\mathrm{C}$

'The maximal degree $d$ s.t. John bought d-many apples exceeds $C$.'

Too in comparative quantification in the nominal domain can take a differential MP, as in John bought three too many apples. As proposed above, assuming that a 
differential MP is an argument of the comparative quantifier too, the compositional semantics of this sentence can be spelled out as in (43). Following the analysis proposed in section 3, I modify the semantics of MANY as in (43)a. ${ }^{15}$

LF: [DegP three too $]_{1}\left[\right.$ [P John bought [DP $t_{1}$ many apples]]

a. $\llbracket M A N Y \rrbracket=\lambda d_{d} \cdot \lambda x_{e} \cdot \mu(x)=d$

b. $\llbracket 1 \mathrm{IP} \rrbracket^{\mathrm{g}}=\lambda \mathrm{d}_{\mathrm{d}} . \exists \mathrm{y}\left[{ }^{*} \operatorname{apple}(\mathrm{y}) \wedge \mu(\mathrm{y})=\mathrm{g}(1) \wedge * \operatorname{buy}(\mathrm{j}, \mathrm{y})\right]$

c. $\llbracket$ three too $\rrbracket^{\mathrm{g}}=\lambda \mathrm{D}^{\prime}<\mathrm{d}, \mathrm{t}>$. $\max \left(\mathrm{D}^{\prime}\right)-\mathrm{C}=3$

d. $\max \{\mathrm{d}: \exists \mathrm{y}[* \operatorname{apple}(\mathrm{y}) \wedge \mu(\mathrm{y})=\mathrm{d} \wedge *$ buy $(\mathrm{j}, \mathrm{y})]\}-\mathrm{C}=3$

'The maximal degree $\mathrm{d}$ s.t. John bought d-many apples exceeds $\mathrm{C}$ by 3 .'

I now direct our attention to an intriguing semantic differences between too many and too much. In (44)a, we obtain the reading spelled out in (43), that is, John exceeded the number of apples that he was supposed to buy by three. ${ }^{16}$ In contrast, (44)b has an additional reading that John exceeded the amount of stuff that he was supposed to buy by three apples, which I call the stuff reading.

(44) a. John bought three apples too many.

b. John bought three apples too much.

The fact that too much can appear in argument position, as in John bought too much, indicates that it must be a nominal predicate of some sort that can serve as an argument. Moreover, John bought too much roughly means that John bought too much stuff. Too much can take an overt NP as a head, as in too much wine. Thus, I assume that, whenever too much appears in argument position, it takes a covert NP stuff as a head, i.e. too much stuff. I further claim that too much can take a differential MP such as three apples. The intuition behind this claim is that apples functions like a classifier in Japanese. The LF of (44)b with the covert NP stuff is given in (45), which is similar to the LF of (44)a given in (43).

LF: [DegP three apples too $]_{1}$ [IP John bought [DP $t_{1}$ much (stuff)]

a. $\llbracket \mathrm{t}_{1}$ much $\left(\right.$ stuff) $\rrbracket^{\mathrm{g}}=\lambda \mathrm{x}_{\mathrm{e}} \cdot \mu(\mathrm{x})=\mathrm{g}(1)(\wedge \operatorname{stuff}(\mathrm{x}))$

b. $\llbracket 1 \mathrm{IP} \rrbracket^{\mathrm{g}}=\lambda \mathrm{d}_{\mathrm{d}} . \exists \mathrm{y}[\mu(\mathrm{y})=\mathrm{g}(1) \wedge *$ buy $(\mathrm{j}, \mathrm{y})]$

c. $\llbracket$ three apples too $\rrbracket^{\mathrm{g}}=\lambda \mathrm{D}^{\prime}<\mathrm{d}, \mathrm{t}>$. $\max \left(\mathrm{D}^{\prime}\right)-\mathrm{C}=3$ apples

d. $\max \{\mathrm{d}: \exists \mathrm{y}[\mu(\mathrm{y})=\mathrm{d} \wedge$ *buy $(\mathrm{j}, \mathrm{y})]\}-\mathrm{C}=3$ apples

'The maximal degree $d$ such that John bought d-much stuff exceeds $C$ by three apples.'

The question arises as to why the stuff reading is unavailable in (44)a. Recall that the interpretation of (44)a is the same as the one of John bought three too many apples. Given the semantic similarity between the two sentences, I propose that these two sentences are derived by an NP-deletion from the same underlying structure, as in (46). 
a. John bought three apples too many apples.

b. John bought three too many apples.

Too many is a complex comparative quantifier that combines with an NP, as in too many apples in (43). Moreover, as we saw in (45), we can consider three apples to be a differential MP, as shown in (47). Although (47) is different from (43) in that the differential MP is three apples, not three, the denotations in (47) and in (43) are almost identical. Hence, it is natural to assume the underlying structure [John bought three apples too many apples]. I suggest that there is a constraint that prohibits having two identical NPs in the surface form. Depending on which NP is deleted, we obtain either John bought three apples too many or John bought three too many apples, as in (46). In contrast, the comparative construction with too much does not involve an NP-deletion. ${ }^{17}$ As proposed in (45), the DegP too much in John bought three apples too much takes the differential MP three apples, and the DegP combines with the covert NP stuff.

LF: [DegP three apples too $]_{1}$ [IP John bought [DP $t_{1}$ many apples]]

a. $\llbracket 1 \mathrm{IP} \rrbracket^{\mathrm{g}}=\lambda \mathrm{d}_{\mathrm{d}} . \exists \mathrm{y}[* \operatorname{apple}(\mathrm{y}) \wedge \mu(\mathrm{y})=\mathrm{g}(1) \wedge * \operatorname{buy}(\mathrm{j}, \mathrm{y})]$

b. $\llbracket$ three too $\rrbracket^{\mathrm{g}}=\lambda \mathrm{D}^{\prime}<\mathrm{d}, \mathrm{t}>$. $\max \left(\mathrm{D}^{\prime}\right)-\mathrm{C}=3$ apples

c. $\max \left\{\mathrm{d}: \exists \mathrm{y}\left[* \operatorname{apple}(\mathrm{y}) \wedge \mu(\mathrm{y})=\mathrm{d} \wedge{ }^{*}\right.\right.$ buy $\left.\left.(\mathrm{j}, \mathrm{y})\right]\right\}-\mathrm{C}=3$ apples

'The maximal degree $\mathrm{d}$ such that John bought d-many apples exceeds $\mathrm{C}$ by three apples.'

Just like too many in English, the V-sugiru in Japanese lacks the stuff reading: (48)a has the same reading as (44)a, that is, John exceeded the number of apples that he was supposed to buy by three. The denotation of this sentence is given in (48)b, based on the analysis proposed in section 3.3. (48)b is analyzed as comparative quantification in the verbal domain, where san-ko 'three-CL' as a differential MP specifies that the measure function is cardinality-of-individuals, hence there needs to be a homomorphism $h$ from events to individuals. The lack of the stuff reading is due to this homomorphism: since $h$ is a homomorphism from buying events to apples, the differential MP must be necessarily associated with apples. In sum, although the English too many construction and Japanese V-sugiru construction both lack the stuff reading, the absence is explained by different systems: while too many involves comparative quantification in the nominal domain, -sugiru involves comparative quantification in the verbal domain. ${ }^{18}$
a. John-ga
ringo-o
san-ko
kai-sugi-ta.
John-NOM
apple-ACC
three-CL
buy-exceed-PAST
'John bought three apples too many.'
b. $\max \{\mathrm{d}: \exists \mathrm{e} \exists \mathrm{x}[\operatorname{Agent}(\mathrm{e})=\mathrm{j} \wedge * \operatorname{apple}(\mathrm{x}) \wedge * \operatorname{buy}(\mathrm{x}, \mathrm{e}) \wedge \mu(h(\mathrm{e}))=\mathrm{d}]\}-$ $\mathrm{C}=3$ individuals


'The maximal degree $d$ such that there is a plural John's buying event $\mathrm{e}$ which is mapped to d-many individuals (namely, apples) exceeds $\mathrm{C}$ by three individuals.'

\section{Conclusion}

The central claim in this paper is that the V-sugiru construction is an instance of comparative quantification in the verbal domain. Extending the analysis of -sugiru with an adjective, I argued that -sugiru with a verb is a comparative quantifier like too in English. Furthermore, since verbal predicates generally do not have a degree argument, I proposed a component relating events with degrees, parallel to MANY introduced in section 2.2 that relates individuals with degrees in complex determiners. This parallelism is illustrated in (49).

a. In the nominal domain

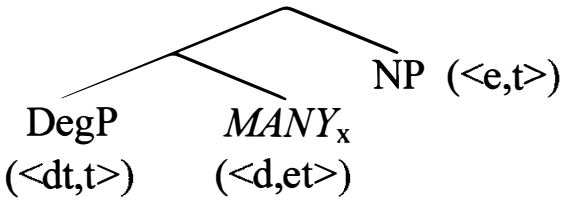

b. In the verbal domain

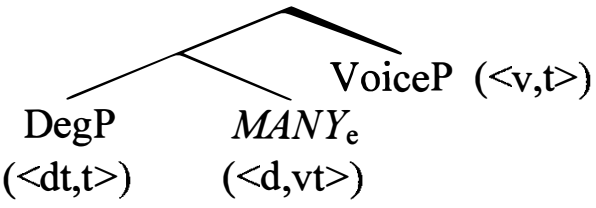

Another important claim made in this paper is that the V-sugiru construction involves a mechanism of measurement in the verbal domain using a homomorphism from events to another domain. Independently, I argued in Nakanishi (2003, 2004, in press) that the floating quantifier construction in Japanese and Split NP Topicalization in German measure in the verbal domain with the help of a homomorphism from events to another domain. Thus, I would like to emphasize that the proposed mechanism is not just needed for one particular construction, but it applies to a range of empirical data.

\section{Endnotes}

I would like to thank Maribel Romero, Irene Heim, Chris Kennedy, and Shoichi Takahashi for valuable comments and discussions. Thanks are also due to the audience at SALT 14.

1 MPs can be interpreted either as a degree argument or as a set of degrees (Hackl 2000:50). $\left\{d: d=6^{\prime}\right\}$ is a singleton $\left\{6^{\prime}\right\}$, hence $\max \left\{d: d=6^{\prime}\right\}$ is equal to $6^{\prime}$.
(i) $\llbracket$ six feet $\rrbracket=6$ '
(ii) $\llbracket$ six feet $\rrbracket=\lambda \mathrm{d}_{\mathrm{d}} \cdot \mathrm{d}=6^{\prime}$

2 Following Heim and Kratzer (1998), I assume that the trace is a variable and that it is bound by an index adjoined right below the moved phrase. I use the Predicate Abstraction Rule defined in (i) and the Trace and Pronouns Rule defined in (ii). 
(i) Predicate Abstraction Rule: Let $\alpha$ be a branching node with daughters $\beta$ and $\gamma$, where $\beta$ dominates only a numerical index i. Then, for any variable assignment $\mathrm{g}, \llbracket \alpha \rrbracket^{\mathrm{g}}=\lambda \mathrm{x} \in \mathrm{D}$. $\llbracket \gamma \rrbracket^{\mathrm{g} x / \mathrm{i}}$.

(Heim and Kratzer 1998:186)

(ii) Trace and Pronouns Rule: If $\alpha$ is a pronoun or a trace, $g$ is a variable assignment, and $i \in \operatorname{dom}(\mathrm{g})$, then $\llbracket \alpha_{\mathrm{i}} \rrbracket^{\mathrm{g}}=\mathrm{g}(\mathrm{i})$ (Heim and Kratzer 1998:186)

3 Since an MP can be either a degree argument or a set of degrees (see footnote 1), -er can alternatively have the denotation in (i).

(i) $\llbracket-e r \rrbracket=\lambda \mathrm{D}_{<\mathrm{d}, \mathrm{t} .} \cdot \lambda \mathrm{D}^{\prime}<\mathrm{d}, \mathrm{t}>. \lambda \mathrm{D}^{\prime \prime}<\mathrm{d}, \mathrm{t} \cdot \max \left(\mathrm{D}^{\prime \prime}\right)-\max (\mathrm{D})=\max \left(\mathrm{D}^{\prime}\right)$

4 Hackl (2000) later proposes that MANY denotes a gradable determiner, i.e. a degree function that takes a degree argument and returns a determiner meaning:

(i) $\llbracket \mathrm{MANY} \rrbracket=\lambda \mathrm{d}_{\mathrm{d} .} . \lambda \mathrm{P}_{<\mathrm{e}, \mathrm{t} .} . \lambda \mathrm{Q}_{<\mathrm{e}, \mathrm{t}} . \exists \mathrm{x}[\mathrm{P}(\mathrm{x}) \wedge \mathrm{Q}(\mathrm{x}) \wedge|\mathrm{x}|=\mathrm{d}]$

5 For lack of a better notation, I will use the symbol $*$ to refer to verbal pluralization also in natural language, not just in the formal language. For example, boy pluralizes into boys, and dance pluralizes into *dance.

${ }^{6}$ See Nakanishi (2004: Chapter IV) for further advantages of simplifying the semantics of too.

7 The neo-Davidsonian agent head of type $<$ e, vt $>$ and the VP of type $<\mathrm{v}$, $\mathrm{t}>$ are combined by Event Identification in (i).

(i) Event Identification (Kratzer 1996:122)

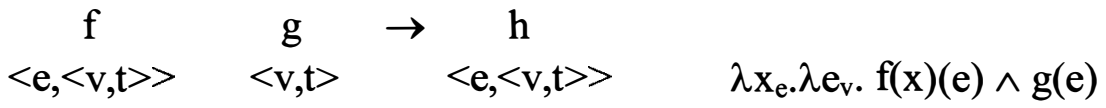

8 Besides introducing comparative quantification like too in English, -sugiru has a kind of negative implication like the prefix over- (e.g. overeat, oversleep) or the adverb excessively in English. See Nakanishi (2004: Chapter IV) for details.

${ }^{9}$ The sentential complement can have a degree argument when it includes a gradable verb (e.g. mijikakusuru 'to shorten') or a gradable adverb (e.g. hayaku 'early'). In this case, MANY is not necessary. See Nakanishi (2004: Chapter IV, section 3.4) for the analysis of this type of comparatives.

${ }^{10}$ When demasiado 'too much' is a nominal modifier, it has to show morphological agreement with the following nominal predicate in terms of gender and number.

${ }^{11}$ A homomorphism is a function that preserves some structural relation defined on its domain in a similar relation defined on the range: a homomorphism of the semilattice $\mathrm{S}_{1}=\left\langle S_{1}, 0>\right.$ into the semilattice $\mathrm{S}_{2}=\left\langle S_{2}, 0>\right.$ is a mapping $F: \mathrm{S}_{1} \rightarrow$ $\mathrm{S}_{2}$ such that $F\left(\mathrm{a}^{\circ} \mathrm{b}\right)=F(\mathrm{a})^{\circ} F(\mathrm{~b})$, where 'o' denotes a composition of two functions (Partee et al. 1990:286).

${ }^{12}$ It has been argued that a homomorphism from one domain to the other is independently required to account for a wide variety of empirical data, such as the semantics of pluractional markers (Lasersohn 1995), of split quantifier constructions in German and Japanese (Nakanishi 2003, 2004, in press), etc.

${ }^{13}$ In Nakanishi (2004: Chapter III, section 4), I argued that verb denotations that are functional relations between individuals and events can serve as a homomorphism from events to individuals. In (37), the denotation of yomu 'to 
read' can be a homomorphism, which is considered to be a function from a reading event to its internal argument hon 'book(s)'.

${ }^{14}$ I ignore event arguments, since they are irrelevant to the semantic of comparative quantification in the nominal domain. See Nakanishi (Chapter IV: section 4) for comparative quantification in the nominal domain with event arguments.

15 The analysis proposed in (43) will be slightly modified in (47) below.

${ }^{16}$ Later in this section, I discuss how (44)a is related to John bought three too many apples.

17 Jason Merchant (p.c.) provided me the following examples indicating that the NP deletion is possible with too many, but not with too much.

(i) a. John revealed too many of his secrets. Bill concealed too many.

b. *John revealed too much of his background. Bill concealed too much.

${ }^{18}$ There is a potential difference between English too many and Japanese -sugiru, which indicate that they involve comparative quantification in different domains. As shown in (i)a, the too many construction can be ambiguous between distributive and collective readings. Differential MPs in the V-sugiru construction cannot generally be associated with external arguments. For this reason, the acceptability of (i)b is controversial. However, some informants accepted it, and judged that only a distributive reading is available. In Nakanishi (2004: Chapter II), I argued that constructions involving measurement in the verbal domain lack a collective reading. Following the same reasoning, the V-sugiru construction lacks a collective reading because it involves quantification in the verbal domain. In contrast, the too many construction involves quantification in the nominal domain, hence it is immune to the constraint on distributivity.

(i) a. Three too many boys carried the piano.

b. Otokonoko-ga

san-nin

piano-o

boy-NOM

three-CL

piano-ACC

$\sqrt{\text { distributive, }} \sqrt{ }$ collective

'Three too many boys carried the piano.'

hakobi-sugi-ta. carry-exceed-PAST

لdistributive, * collective

\section{References}

Davidson, Donald. 1967. The logical form of action sentences. In N. Rescher ed., The Logic of Decision and Action, 81-95. Pittsburgh: University of Pittsburgh Press.

Downing, Pamela. 1996. Numeral Classifier Systems: The Case of Japanese. Amsterdam: John Benjamins.

Hackl, Martin. 2000. Comparative Quantifiers. Ph.D. dissertation, MIT.

Heim, Irene. 2000. Degree operators and scope. The Proceedings of Semantics and Linguistics Theory $X, 40-64$.

Heim, Irene, and Angelika Kratzer. 1998. Semantics in Generative Grammar. Oxford: Blackwell. 
Kageyama, Taro, and Yoko Yumoto. 1997. Gokeisei to Gainen Kozo [Word Formation and Conceptual Structure]. Tokyo: Kenkyusha.

Kennedy, Christopher. 1999. Projecting the Adjective: The Syntax and Semantics of Gradability and Comparison. New York: Garland.

Koizumi, Masatoshi. 1998. Invisible Agr in Japanese. The Linguistic Review 15, $1-37$.

Kratzer, Angelika. 1996. Severing the external argument from its verb. In J. Rooryck and L. Zaring eds., Phrase Structure and the Lexicon, 109-137. Dordrecht: Kluwer.

Kratzer, Angelika. to appear. The Event Argument and the Semantics of Verbs.

Krifka, Manfred. 1989. Nominal reference, temporal constitution and quantification in event semantics. In R. Bartsch, J. van Benthem and P. van Emde Boas eds., Semantics and Contextual Expression, 75-115. Dordrecht: Foris.

Krifka, Manfred. 1995. Common nouns in Chinese and English. In G. Carlson and F. J. Pelletier eds., The Generic Book, 398-411. Chicago: University of Chicago Press.

Lasersohn, Peter. 1995. Plurality, Conjunction and Events. Dordrecht: Kluwer.

Link, Godehard. 1983. The logical analysis of plural and mass terms: A lattice theoretic approach. In R. Bäuerle, C. Schwarze and A. von Stechow eds., Meaning, Use and Interpretation of Language, 302-323. Berlin: de Gruyer.

Meier, Cècile. 2003. The meaning of too, enough, and so ... that. Natural Language Semantics 11, 69-107.

Nakanishi, Kimiko. 2003. The semantics of measure phrases. M. Kadowaki and S. Kawahara eds., The Proceedings of the 33rd Conference of the North East Linguistic Society (NELS 33), 225-244.

Nakanishi, Kimiko. 2004. Domains of Measurement: Formal Properties of Non-Split/Split Quantifier Constructions. Ph.D. dissertation, University of Pennsylvania.

Nakanishi, Kimiko. in press. Semantic properties of Split Topicalization in German. In C. Maienborn and A. Wöllstein-Leisten eds., Events in Syntax, Semantics, and Discourse. Tubingen: Niemeyer.

Partee, Barbara. 1987. Noun phrase interpretation and type-shifting principles. In J. Groenendijk, D. de Jongh and M. Stokhof eds., Studies in Discourse Representation Theory and the Theory of Generalized Quantifiers, 115-143. Dordrecht: Foris.

Partee, Barbara, Alice ter Meulen, and Robert Wall. 1990. Mathematical Methods in Linguistics. Dordrecht: Kluwer.

Rullmann, Hotze. 1995. Maximality in the Semantics of WH-Constructions. Ph.D. dissertation, University of Massachusetts, Amherst.

Schwarzschild, Roger. 2002. The grammar of measurement. The Proceedings of Semantics and Linguistics Theory XII, 225-245.

von Stechow, Arnim. 1984. My reaction to Cresswell's, Hellan's, Hoeksema's and Seuren's comments. Journal of Semantics 3, 183-199.

Sugioka, Yoko. 1985. Interaction of Derivational Morphology and Syntax in Japanese and English. New York: Garland. 